\title{
Materiales compuestos en arquitectura recursos e impacto ambiental
}

\author{
pags 153-173 \\ Grupo de investigación: Territorio y habitabilidad \\ Línea de investigación: Arquitectura, ciudad y ambiente \\ Oscar Cortés-Cely, Luis Fernando Molina-Prieto•
}

Recibido: 4 de noviembre de 2014

Aceptado: 5 de diciembre de 2014

\begin{abstract}
RESUMEN
El artículo aborda el tema de los Materiales Compuestos con miras a su aplicación en la arquitectura, haciendo énfasis en dos aspectos: 1. definición, clasificación, propiedades mecánicas y térmicas, y usos en arquitectura de los Materiales Compuestos; y 2. análisis del ciclo de vida de algunas de las materias primas que los conforman. Se busca establecer si los Materiales Compuestos, al ser incluidos en los proyectos arquitectónicos, contribuyen a disminuir el impacto ambiental generado por la industria de la construcción o si, por el contrario, aportan mayores cargas ambientales contaminantes. Se indaga sobre tres clases de Materiales Compuestos: los de matriz metálica, los de matriz cerámica y los de matriz orgánica. Para la evaluación del ciclo de vida se recurre al software SimaPro. Se concluye que los Materiales Compuestos de matriz orgánica generan bajo impacto ambiental; los de matriz cerámica, impacto medio; y los de matriz metálica, alto impacto.
\end{abstract}

Palabras clave: Materiales compuestos, ciclo de vida, impacto ambiental.

\begin{abstract}
The article takes the topic of Composite Materials for its application in architecture and emphasizes two aspects: 1. definition, classification, mechanical and thermal properties, and uses in architecture of Composite Materials; and 2. life cycle analysis of some of the raw materials that make up. It seeks to establish whether the Composite Materials, to be included in the architectural projects, contribute to reducing the environmental impact caused by the construction industry or whether, on the opposite, provide greater environmental pollutants loads. It explores three kinds of composite materials: metal matrix, ceramic matrix and organic matrix. For the life cycle assessment, SimaPro software is used. It is concluded that the organic matrix composite materials, generate low environmental impact; the ceramic matrix, medium impact; and the metallic matrix, high impact.
\end{abstract}

Key words: Composite Material, life cycle, environmental impact.

- Investigador ingeniería Industrial, Fundación Universidad de América. Luis.sanchez@profesores.uamerica.edu.co 


\section{INTRODUCCIÓN}

En el mundo, la construcción de vivienda convencional, se utilizan materiales tradicionales que demandan gran cantidad de recursos naturales y de energía no renovable:

"La industria de la construcción consume el $50 \%$ de los recursos mundiales, actividad que se convierte en la menos sostenible del planeta" (Edwards, 2005. P. 18).

De manera reciente han aflorado en el campo de la ingeniería mecánica los Materiales Compuestos, que incrementan la resistencia mecánica, la flexibilidad, o la dureza de los materiales que los conforman. Estos nuevos materiales surgen como una interesante opción para la arquitectura, especialmente para la industria de la construcción, lo que podría significar un gran aporte en cuanto a la producción de vivienda a nivel global.

La ciencia de los Materiales Compuestos les confiere algunas propiedades que superan a los materiales simples, pues al combinar, dos o más materiales, se logran propiedades que alcanzan altos niveles de rigidez, resistencia mecánica, rendimiento a altas temperaturas, resistencia a la corrosión y dureza (Da Costa, Velasco \& Torralba, 2000). La creación de nuevos materiales utiliza y aplica recursos derivados de la naturaleza para fabricar dispositivos de alta tecnología, lo cual ha permitido grandes avances a partir de la física cuántica y de la nanociencia (Takeuchi, 2010). Los Materiales Compuestos alcanzan una gran eficiencia mecánica; son de fácil mantenimiento y durables; Sin embargo, muchos de sus componentes aportan agentes contaminantes al ambiente, en detrimento de los ecosistemas y la biodiversidad.

El propósito del artículo es realizar una aproximación a los Materiales Compuestos, con miras a su aplicación en la arquitectura, lo que incluye dos aspectos: 1. definición, clasificación, propiedades mecánicas y térmicas, y usos en arquitectura; y 2. análisis del ciclo de vida de algunas de las materias primas que los conforman. De esta manera el artículo busca establecer si los Materiales Compuestos, al ser incluidos en la arquitectura, contribuyen a disminuir el impacto ambiental generado por la industria de la construcción o si, por el contrario, aportan mayores cargas ambientales contaminantes. Se indaga sobre tres clases de Materiales Compuestos: los metálicos, los cerámicos y los orgánicos, según la clasificación propuesta por Mott (2009, p. 91).

\section{Los materiales compuestos}

"Se entiende por material compuesto aquel formado por dos o más componentes, de forma que las propiedades del material final sean superiores que las de los componentes por separado" (Miravete \& Castejón, 2002).

En todo material compuesto se distinguen dos componentes: la MATRIZ, que actúa como adherente; y el REFUERZO, que es el elemento que aporta la resistencia. Los Materiales Compuestos han incursionado en diversos ámbitos del desarrollo, desde la industria aeronáutica hasta la nanotecnología.

"El objetivo que se persigue con este tipo de materiales es la mejora, fundamentalmente, de las propiedades mecánicas del compuesto (resistencia mecánica, flexibilidad, dureza, etc.) en relación con las de sus componentes, matriz y refuerzo, combinando su morfología y su distribución" (Materiales compuestos, 2014).

\section{Clasificación de los materiales compuestos}

Los Materiales Compuestos se clasifican a partir del material predominante, que actúa como adherente y como ya se mencionó, se conoce como MATRIZ (ver Figura 1). Existen tres categorías principales: los de matriz metálica, los de matriz cerámica y los de matriz orgánica. A continuación se presentan los materiales que componen cada una de esas categorías. 
LÍNEA DE INVESTIGACIÓN: ARQUITECTURA, CIUDAD Y AMBIENTE

Figura 1: Diagrama de la clasificación de los materiales compuestos

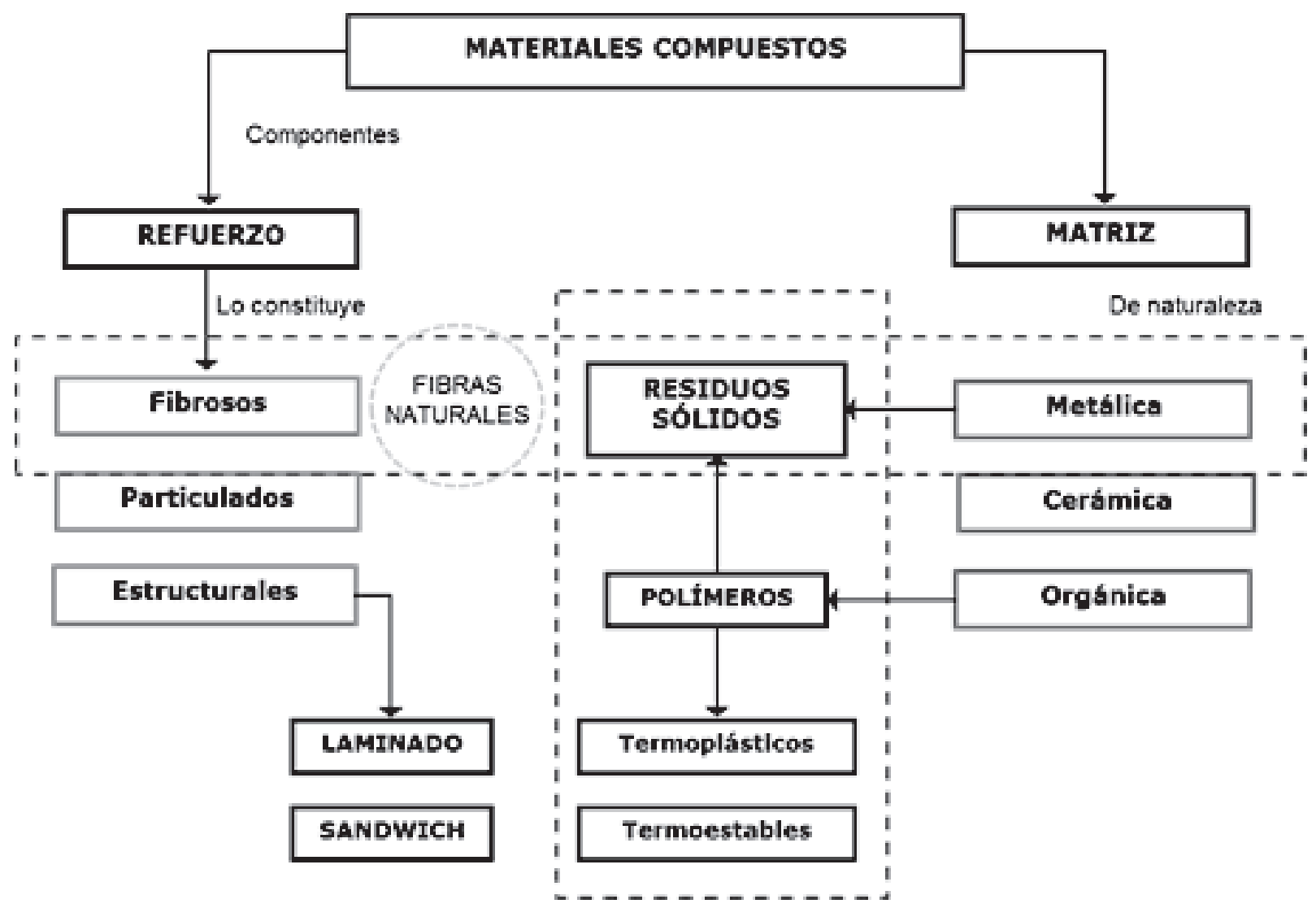

Fuente: A partir de la clasificación realizada por Mott, 2009.

\section{Materiales compuestos de matriz metálica}

Los Materiales Compuestos de matriz metálica son utilizados principalmente en las industrias aeroespacial y automotriz. Trabajan con aleaciones entre metales ligeros y fibras, que contribuyen a la resistencia a grandes esfuerzos de tracción y flexión.

La densidad varía de acuerdo a la materia prima. Están conformados principalmente por cuatro métales ligeros: aluminio, titanio, magnesio y berilio (ver Figura 2).

El aluminio es el tercer elemento más común después del silicio y el oxígeno. Constituye cerca del $8 \%$ de la corteza terrestre. Por ser un metal ligero, dúctil y maleable, blando pero fuerte, resistente a la corrosión y buen conductor eléctrico y del calor, es utilizado actualmente en las industrias aeronáutica, automotriz, naval y de la construcción, y además, en el sector eléctrico (cables de trasmisión de alta tensión) y el de envases (latas para bebidas, papel de aluminio para preservar alimentos). El titanio, en forma de óxido y rocas ígneas, es el cuarto metal más abundante en la naturaleza, y es el noveno elemento más abundante en la corteza terrestre. Por ser un material liviano que posee alta resistencia mecánica y además, ser muy resistente a la corrosión, es utilizado en las industrias aeroespacial, naval y militar, médica y odontológica (instrumentos quirúrgicos, implantes), y de manera reciente en la industria de la construcción, como en el Museo Guggenheim de Bilbao (Ingeniería mecánica, 2014). El magnesio es considerado el séptimo 
elemento más abundante en la corteza terrestre. Por su baja densidad (30\% inferior a la del aluminio), dureza y alta resistencia a la corrosión, es uno de los materiales más utilizados en la industria metalmecánica. En aleaciones se usa en la industria aeroespacial, automotriz, naval, de artículos deportivos, de telecomunicaciones (partes de teléfonos celulares). Por último, el berilio, se emplea principalmente en aleaciones por su dureza, alta resistencia al calor y a la corrosión. En la industria aeronáutica y aeroespacial, el berilio se utiliza ampliamente por sus propiedades de ligereza, rigidez y estabilidad dimensional (Elementos químicos, 2014).

Las Propiedades físicas y térmicas de las materias primas de los Materiales Compuestos de matriz metálica, se presentan en la Tabla 1. Las principales características de los compuestos de matriz metálica son: alta resistencia y rigidez, bajo peso, alta conductividad térmica, bajo coeficiente de expansión térmica e inerte a la oxidación y ataque químico.

Figura 2: Componentes de la matriz metálica

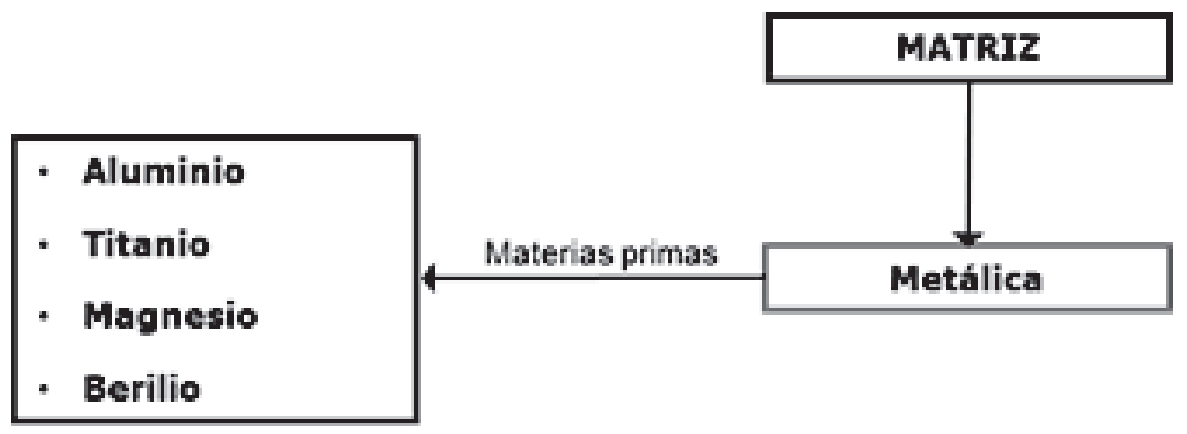

Fuente: A partir de la clasificación realizada por Mott, 2009.

Tabla 1: Propiedades físicas y térmicas de las materias primas de Materiales Compuestos de matriz metálica. Elaboración propia

\begin{tabular}{|c|c|c|c|c|c|c|c|}
\hline \multirow{2}{*}{ Matriz } & & \multirow{2}{*}{$\begin{array}{c}\text { Materia } \\
\text { prima }\end{array}$} & \multicolumn{3}{|c|}{ Propiedades físicas } & \multicolumn{2}{|c|}{ Propiedades térmicas } \\
\hline & & & Densidad & $\begin{array}{l}\text { Punto de } \\
\text { fusión }\end{array}$ & $\begin{array}{l}\text { Punto de } \\
\text { ebullición }\end{array}$ & $\begin{array}{c}\text { Calor } \\
\text { específico }\end{array}$ & $\begin{array}{c}\text { Conductividad } \\
\text { térmica (K) }\end{array}$ \\
\hline Metálica & \multirow{4}{*}{ 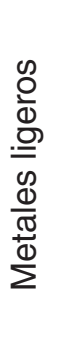 } & Aluminio & $2700 \mathrm{~kg} / \mathrm{m}^{3}$ & $660^{\circ} \mathrm{C}$ & $2480^{\circ} \mathrm{C}$ & $9001 /(\mathrm{K}-\mathrm{KG})$ & 237 w(K-m) \\
\hline & & Titanio & 4507 kg/m³ & $1668^{\circ} \mathrm{C}$ & $3560 \mathrm{~K}$ & 520 1/(K-kg) & $21,9 \mathrm{~W} /(\mathrm{K}-\mathrm{m})$ \\
\hline & & Magnesio & $1738 \mathrm{~kg} / \mathrm{m}^{3}$ & $650^{\circ} \mathrm{C}$ & $1090^{\circ} \mathrm{C}$ & 1020 1/(K-kg) & $156 \mathrm{~W} /(\mathrm{K}-\mathrm{m})$ \\
\hline & & Berilio & $1848 \mathrm{~kg} / \mathrm{m}^{3}$ & $1287^{\circ} \mathrm{C}$ & $2969^{\circ} \mathrm{C}$ & 1825 1/(K-kg) & 201 W/(K-m) \\
\hline
\end{tabular}

Fuente: Educacion.es 
LÍNEA DE INVESTIGACIÓN: ARQUITECTURA, CIUDAD Y AMBIENTE

\section{Usos en la arquitectura de los materiales compuestos de matriz metálica}

Aluminio: Es el metal ligero que mayor aplicación tiene en la industria de la construcción. Los perfiles extruidos se emplean tradicionalmente en diversas aplicaciones arquitectónicas, especialmente en la fabricación de puertas, ventanas, claraboyas, y marquesinas. También se emplea como material de fachada, a partir de paneles tipo sándwich, que varían de espesor de acuerdo a la necesidad y aplicación arquitectónica. (www.alucobond, 2014).
Titanio: Las láminas de titanio han sido utilizadas para revestir fachadas en varios proyectos de arquitectura de vanguardia. Entre los más destacados se cuentan los proyectos del arquitecto Frank Gehry: el Museo Aeroespacial de California (1982-1984), el Centro Americano en París (1994), el Museo de Arte de Weisman y la sala de conciertos de Walt Disney en Los Ángeles, aunque:

“(...) el edificio que le reportó mayor prestigio internacional fue el Museo Guggenheim de Bilbao (1991-1997), en el que empleó cristal, acero inoxidable, zinc y titanio, mezclados con otros materiales autóctonos como la piedra".

(Guggenheim-Bilbao.es)

Figura 3: Aplicación del Aluminio en la Fachada del Medicina Penn Washington Square, Alucobond Plus, Philadelphia, Pennsylvania, 2013.
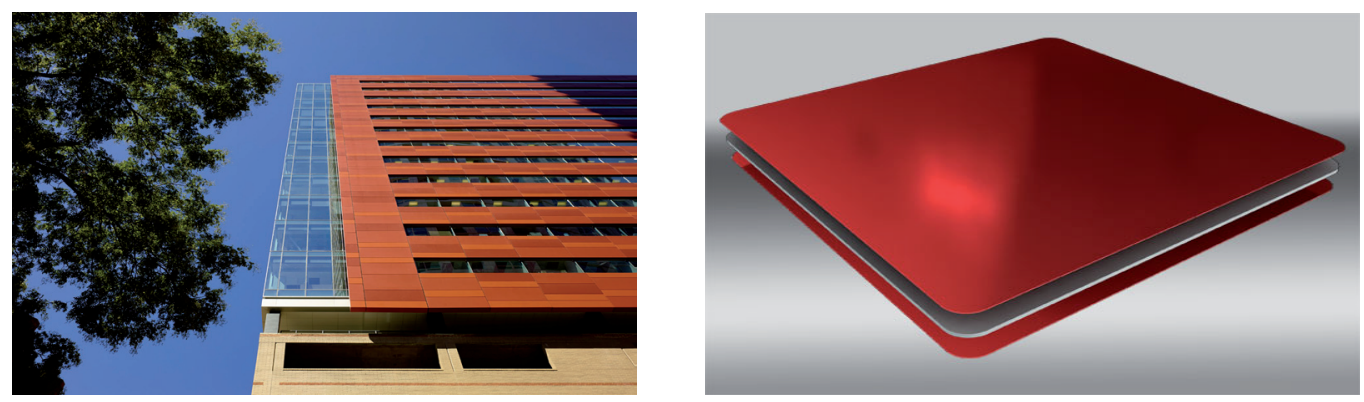

Fuente: Alucobondusa.com

Figura 4: Aplicación del Aluminio en perfiles extruidos para ventanas, 2014.
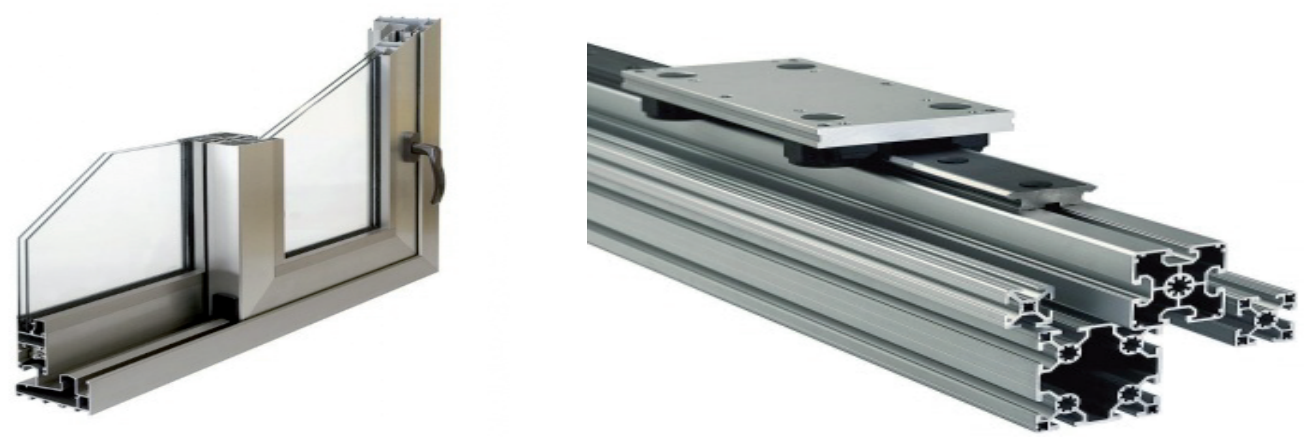

Fuente: Wikifab.es 


\section{Materiales Compuestos de matriz cerámica}

Los Materiales Compuestos de matriz cerámica se caracterizan por su gran desempeño térmico y soportan temperaturas entre los 1200 hasta 1800 grados centígrados, propiedad que los hace muy valorados en aplicaciones industriales con requerimientos extremos. Las usos más importantes son: aislantes térmicos de motores de propulsión a chorro de los jets comerciales y de cohetes espaciales y militares; elementos estructurales en las turbinas de gas para plantas de generación de potencia y frenos en vehículos de carreras (Ciencia y Desarrollo, 2014).

Los componentes primarios que conforman la matriz cerámica son el silicio, el dióxido de silicio (o sílice), la alúmina, el calcio y el sodio (ver Figura 6).

El silicio es el segundo elemento más abundante en la corteza terrestre, después del oxígeno. En estado puro se considera un metaloide, elemento químico semiconductor, propiedad que lo hace muy requerido en la industria de la computación y las telecomunicaciones para la producción de chips, fibras ópticas y circuitos electrónicos (Sílicon Valley). Además, es elemento esencial para la fabricación de paneles fotovoltaicos. En aleaciones se emplea para la fabricación de siliconas, muchas de ellas utilizadas en la industria de la construcción. El dióxido de silicio (o sílice), se encuentra en la naturaleza como parte de la arena, el cuarzo y diversas piedras y arcillas. Se emplea de manera importante en la fabricación del vidrio, las cerámicas y el cemento portland. Por los tanto, es un material esencial en la arquitectura y la industria de la construcción. La alúmina (óxido de aluminio), junto con el dióxido de silicio (o sílice), son los componentes más importantes de las arcillas y los esmaltes. La alúmina es un metaloide más duro que el aluminio que se utiliza como base para la producción de ese metal. Por su dureza (está presente en piedras preciosas como el rubí y el zafiro) la alúmina se emplea para la fabricación de materiales abrasivos, y por sus características químicas, como fundente en la producción de diversas aleaciones. El calcio es el quinto elemento más abundante en la corteza terrestre. Se emplea en diversas aleaciones, para aportarles dureza y estabilidad. En la industria de la construcción se usa el calcio en varias de sus

Figura 5: Aplicación del Titanio en fachadas, 2014.

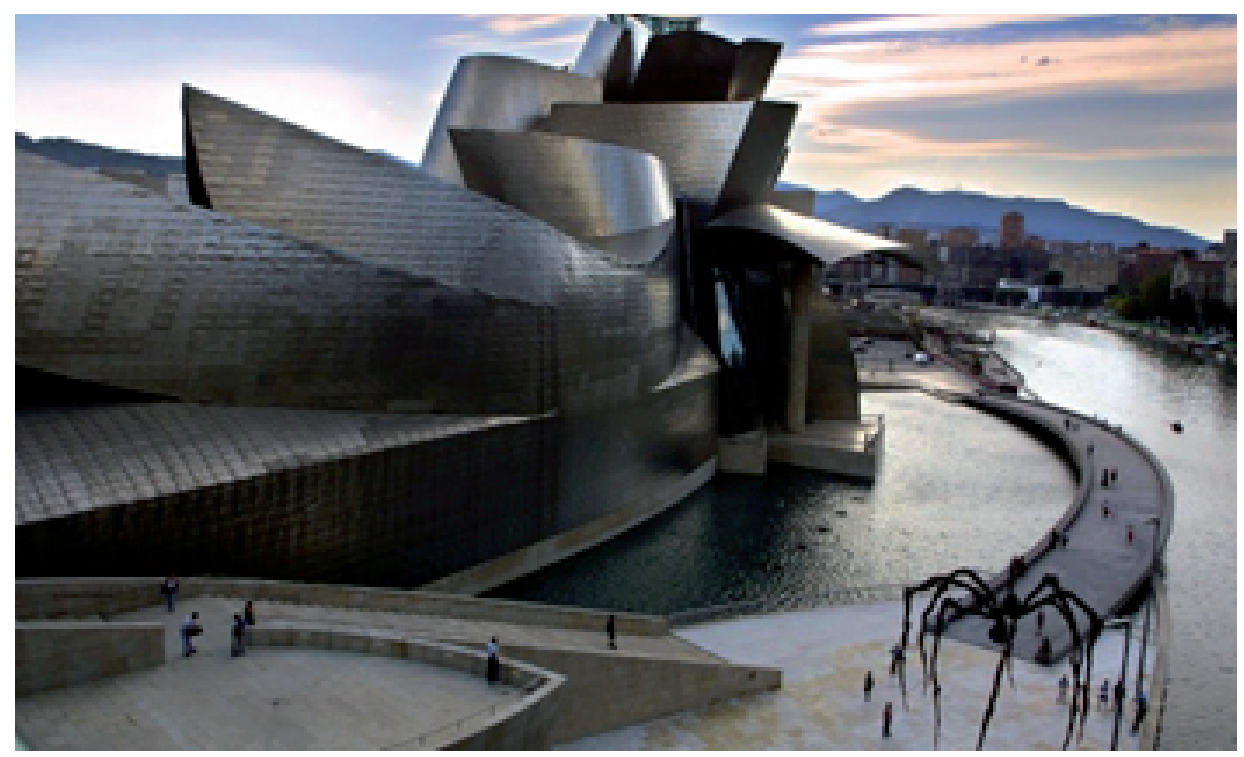

Fuente: Latercera.com 
LÍNEA DE INVESTIGACIÓN: ARQUITECTURA, CIUDAD Y AMBIENTE

manifestaciones, como el yeso (sulfato de calcio hidratado) o el mármol (carbonato de calcio). Por último, el sodio es el sexto elemento más abundante en la corteza terrestre. En estado natural no se encuentra en estado puro, pero hace parte de muchos compuestos como la sal. El sodio es un metal alcalino, blando y ligero, que se emplea en diversas aleaciones. Las Propiedades físicas y térmicas de las materias primas de los Materiales Los compuestos de matriz cerámica, se presentan en la Tabla 2. Las principales características de los compuestos de matriz cerámica son: resistencia a alta temperatura, mayor resistencia y rigidez y resistencia a la corrosión.

Figura 6: Componentes de la matriz cerámica

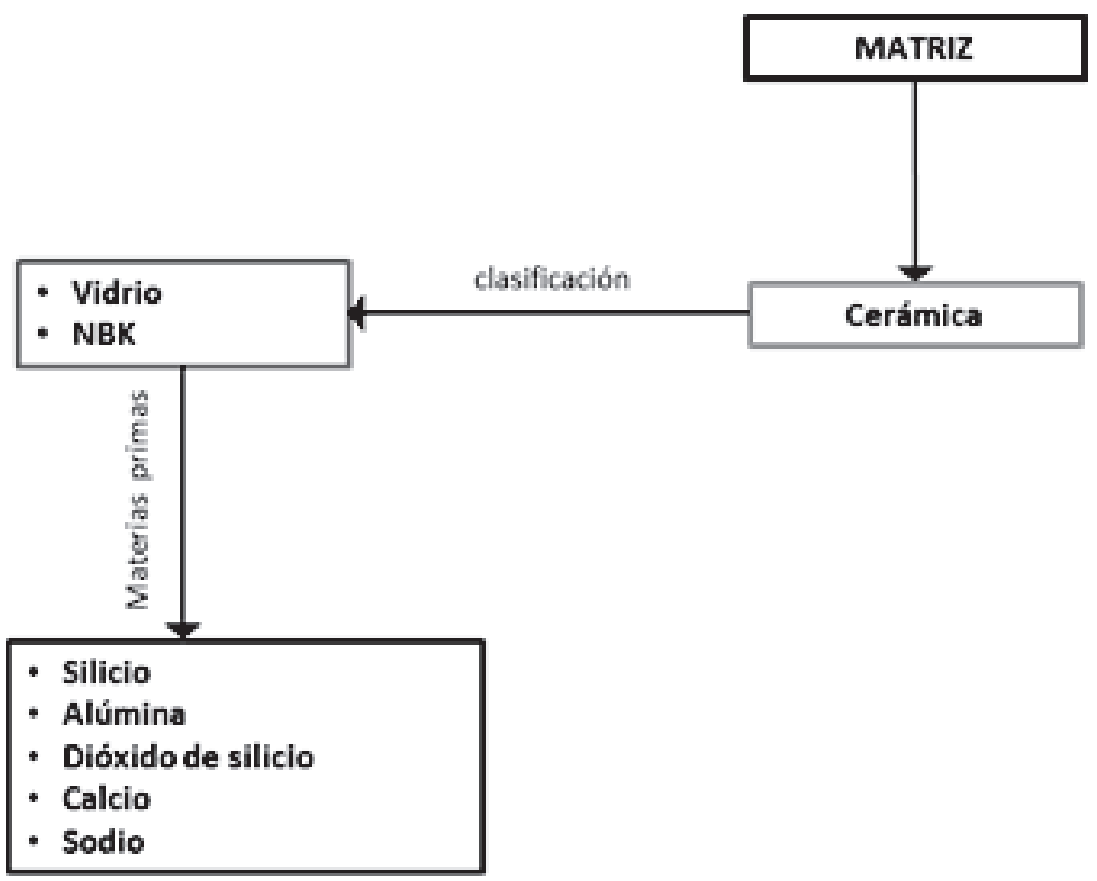

Fuente: A partir de la clasificación realizada por Mott, 2009.

Tabla 2: Propiedades físicas y térmicas de las materias primas de Materiales Compuestos de matriz cerámica.

\begin{tabular}{|c|c|c|c|c|c|c|c|}
\hline \multirow[b]{2}{*}{ Matriz } & & \multirow[b]{2}{*}{ Materia prima } & \multicolumn{3}{|c|}{ Propiedades físicas } & \multicolumn{2}{|c|}{ Propiedades térmicas } \\
\hline & & & Densidad & $\begin{array}{l}\text { Punto de } \\
\text { fusión }\end{array}$ & $\begin{array}{l}\text { Punto de } \\
\text { ebullición }\end{array}$ & $\begin{array}{c}\text { Calor } \\
\text { específico }\end{array}$ & $\begin{array}{c}\text { Conductividad } \\
\text { térmica (K) }\end{array}$ \\
\hline \multirow[t]{5}{*}{ Cerámica } & \multirow{5}{*}{ 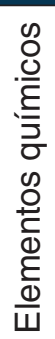 } & Silicio & $2330 \mathrm{~kg} / \mathrm{m}^{3}$ & $917^{\circ} \mathrm{C}$ & $1442^{\circ} \mathrm{C}$ & $7001 /(\mathrm{K}-\mathrm{KG})$ & $148 \mathrm{w}(\mathrm{K}-\mathrm{m})$ \\
\hline & & Alúmina & $3960 \mathrm{~kg} / \mathrm{m}^{3}$ & $2072^{\circ} \mathrm{C}$ & NR & NR & $24 \mathrm{~W} /(\mathrm{K}-\mathrm{m})$ \\
\hline & & Sílice & $2634 \mathrm{~kg} / \mathrm{m}^{3}$ & $1713^{\circ} \mathrm{C}$ & $2899^{\circ} \mathrm{C}$ & 700 1/(K-kg) & $148 \mathrm{~W} /(\mathrm{K}-\mathrm{m})$ \\
\hline & & Sodio & $968 \mathrm{~kg} / \mathrm{m}^{3}$ & $98^{\circ} \mathrm{C}$ & $883^{\circ} \mathrm{C}$ & 1230 1/(K-kg) & $141 \mathrm{~W} /(\mathrm{K}-\mathrm{m})$ \\
\hline & & Calcio & $1550 \mathrm{~kg} / \mathrm{m}^{3}$ & $842^{\circ} \mathrm{C}$ & $1526^{\circ} \mathrm{C}$ & $0,6321 /(\mathrm{K}-\mathrm{kg})$ & $201 \mathrm{~W} /(\mathrm{K}-\mathrm{m})$ \\
\hline
\end{tabular}

Fuente: A partir de Educación.es 


\section{Usos en la arquitectura de los materiales compuestos de matriz ceráma}

NBK: Los avances tecnológicos en el ámbito del uso de Materiales Compuestos de matriz cerámica en la arquitectura los ha liderado NBK, empresa holandesa que produce paneles terracota para fachadas donde se mezclan la tradición de la arcilla como materia prima base con la última tecnología en fachadas ventiladas. Las baldosas de terracota de NBK (Hunter Douglas, 2014), ofrecen una variedad de tamaños, formas, colores y acabados, aplicaciones que incluyen formatos: grande, medio, baguette, sólido y los sistemas de shingle.

Vidrio: La tecnología del vidrio permite funciones estructurales, decorativas y bioclimáticas. El vidrio logra mejorar el confort interior de los espacios con sistemas adaptables a diferentes condiciones climáticas. Es el material que más se utiliza en la arquitectura contemporánea, sus aplicaciones van desde la envolvente principal del edificio, divisiones interiores, barandas y escaleras hasta persianas digitales, tecnología desarrollada por Phillips (2007), quien diseño dos prototipos:

“(..) un primer prototipo llamado Daylight Window, (...) se trata de un vidrio que es capaz de reproducir tanto luces como sombras en distintos niveles y operado de una manera totalmente digital (...) un segundo prototipo fue desarrollado por el MIT, en conjunto con la Fundazione Bruno Kessler (...) permite controlar la temperatura y luminosidad, programando la abertura, tiene como principal objetivo la sustentabilidad." (Plataforma arquitectura, 2014).

Figura 7: Aplicación del NBK en la Fachada del Centro Comercial Andino, Bogotá, 2013.
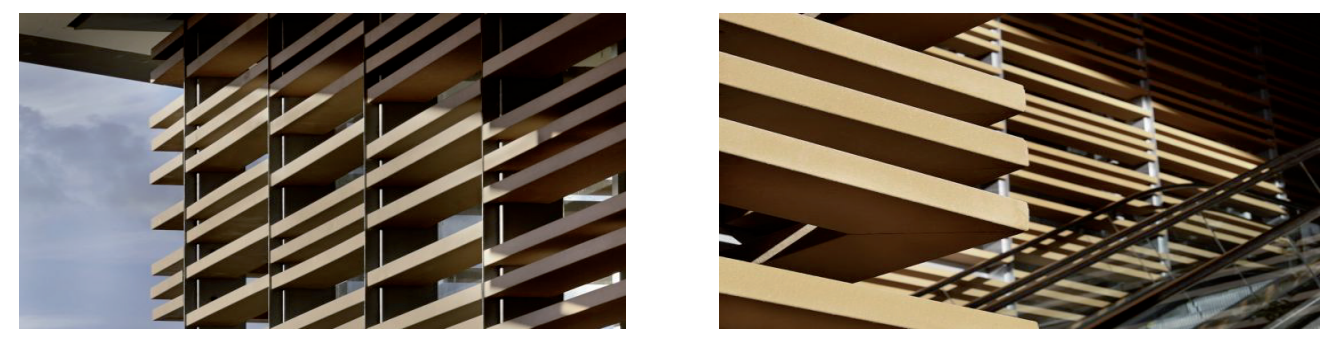

Fuente: Hounterdouglas.com

Figura 8: Aplicación del Vidrio en la arquitectura contemporánea. Edificio Krishna P. Singh Center for Nanotechnology, de la Universidad de Pensilvania, 2013.
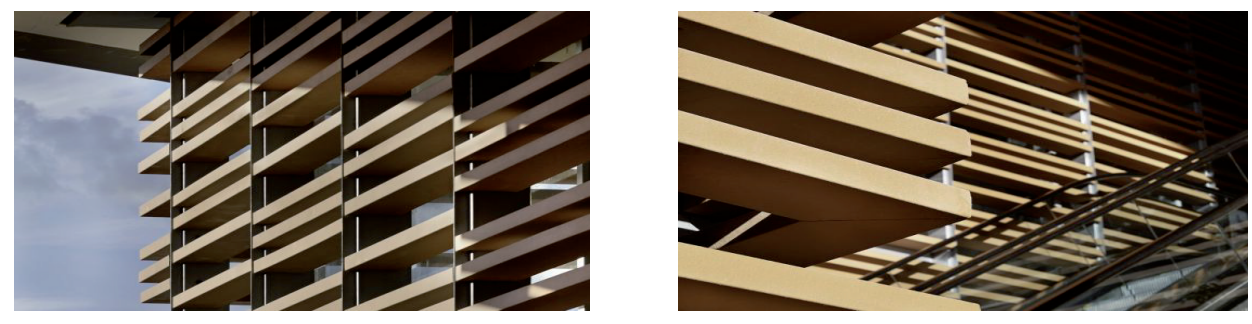

Fuente: Fierasdelaingeniería.com 
LÍNEA DE INVESTIGACIÓN: ARQUITECTURA, CIUDAD Y AMBIENTE

\section{Materiales compuestos de matriz orgánica}

Los Materiales Compuestos de matriz orgánica se clasifican en dos categorías: los polímeros termoestables y los polímeros termoplásticos.

Polímeros termoestables: Los polímeros termoestables tienen la propiedad de no fundirse o deformarse por efecto de presión o temperatura. Su capacidad de reciclaje es nula, pues una vez se han solidificado es imposible retornarlos al estado líquido.

Los principales componentes de los polímeros termoestables son (ver Figura 9): los fenólicos, las aminas, el poliéster, los epoxis, los uretanos, las siliconas y el poliuretano en espuma. Estos componentes se caracterizan por ser compuestos químicos orgánicos (Tecnología de los plásticos, 2014).

Figura 9: Componentes de la matriz orgánica.
En la industria de la construcción se usan las resinas epoxídicas, que generalmente se comercializan en forma de dos componentes que al mezclarse se solidifican; y las resinas melamínicas, empleadas como recubrimiento de cocinas y refrigeradores.

Las propiedades adherentes y de gran resistencia a esfuerzos, de los polímeros termoestables (ver tabla 3), fomentan su comercialización a nivel mundial con producciones cercanas a los 42 millones de toneladas de poliéster al año, principalmente para la industria textil. En el mundo se producen $8.323 \mathrm{~kg}$ de poliéster cada segundo (Fibras sintéticas y artificiales, 2014). Las principales características de las resinas son: buen aislamiento eléctrico, buena resistencia mecánica, resisten la humedad, resisten el ataque de fluidos corrosivos, resisten temperaturas elevadas, excelente resistencia química, poca contracción al curar y excelentes propiedades adhesivas.

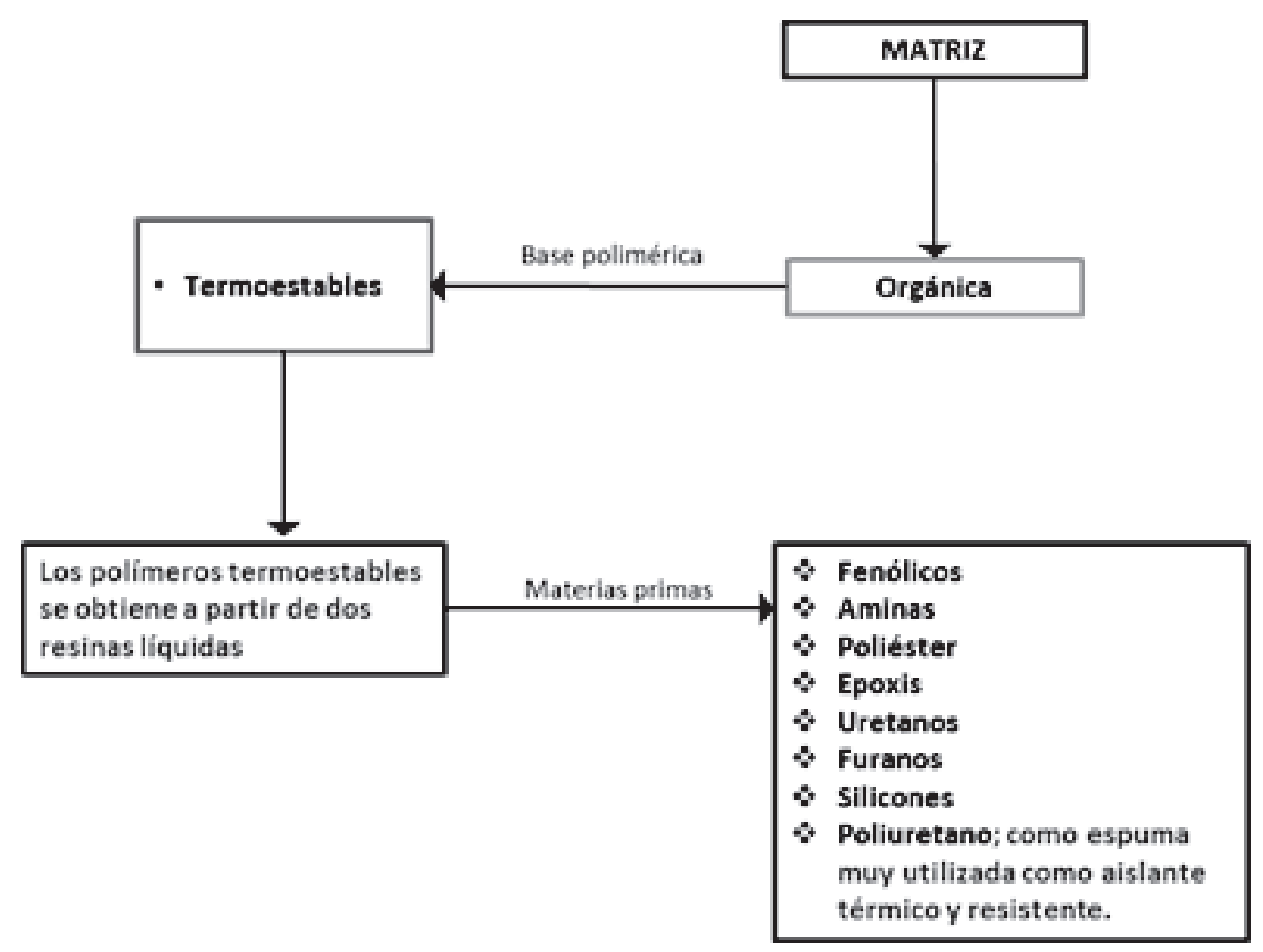

Fuente: Polímeros Termoestables, a partir de la clasificación realizada por Mott, 2009. 
Polímeros termoplásticos: Estos polímeros, a diferencia de los termoestables, pueden calentarse y moldearse, adquiriendo la forma deseada al enfriarse, y este ciclo puede aplicarse muchas veces sin degradar el polímero. Los más usados son (ver Figura 10): el polietileno, el policloruro de vinilo (conocido como PVC), el polipropileno, el poliestireno, el policarbonato, el poliuretano (en molde o extruido), y el politereftalato de etileno. Los polímeros termoplásticos se caracterizan porque poseen, cerca del $10 \%$ con respecto a la de los metales, dureza muy baja; y la ductilidad más alta en promedio, con un tremendo rango de valores, desde una elongación del $1 \%$ para el poliestireno, hasta el $500 \%$ o más para el propileno (Polímeros Termoplásticos, 2014). Los polímeros termoplásticos poseen una estructura que les proporciona propiedades que otros tipos de polímeros no poseen (ver tabla 4) y que los hacen muy útiles para aplicaciones de altas exigencias técnicas tales como: excelente resistencia a la abrasión, excelentes propiedades mecánicas, gran resistencia al desgarre, buena resistencia a agentes químicos y muy buena elasticidad a bajas temperaturas.

Tabla 3: Propiedades físicas y térmicas de las materias primas de Materiales Compuestos de matriz polimérica (Termoestables)

\begin{tabular}{|c|c|c|c|c|c|c|c|}
\hline \multirow[b]{2}{*}{ Matriz } & & \multirow[b]{2}{*}{$\begin{array}{c}\text { Materia } \\
\text { prima }\end{array}$} & \multicolumn{3}{|c|}{ Propiedades físicas } & \multicolumn{2}{|c|}{ Propiedades térmicas } \\
\hline & & & Densidad & $\begin{array}{l}\text { Punto de } \\
\text { fusión }\end{array}$ & $\begin{array}{l}\text { Punto de } \\
\text { ebullición }\end{array}$ & Calor especifico & $\begin{array}{c}\text { Conductividad } \\
\text { térmica (K) }\end{array}$ \\
\hline \multirow[t]{7}{*}{ Orgánica } & & Fenólicos & $1070 \mathrm{~kg} / \mathrm{m}^{3}$ & $41^{\circ} \mathrm{C}$ & $182^{\circ} \mathrm{C}$ & $-26^{\circ} \mathrm{C} 0561 \mathrm{kcal} / \mathrm{mol}^{\circ} \mathrm{K}$ & NR \\
\hline & @ & Aminas & 0,18 & $-20^{\circ} \mathrm{C}$ & 19,13 & NR & NR \\
\hline & 可 & Poliéster & $133 \mathrm{~kg} / \mathrm{m}^{3}$ & $250^{\circ} \mathrm{C}$ & NR & NR & $0,060 \mathrm{~W} / \mathrm{m}$ \\
\hline & $\stackrel{\infty}{\infty}$ & Epoxis & NR & NR & NR & NR & NR \\
\hline & $\stackrel{\circ}{\xi}$ & Uretanos & $1,1 \mathrm{~kg} / \mathrm{m}^{3}$, Sólido & $48-50^{\circ} \mathrm{C}$ & NR & NR & NR \\
\hline & $\stackrel{\bar{\omega}}{\varrho}$ & Furanos & $0,94 \mathrm{~g} / \mathrm{cm}^{3}$ & $-85,6^{\circ} \mathrm{C}$ & 31,3 & NR & NR \\
\hline & & Siliconas & $1,3 \mathrm{~g} / \mathrm{m}^{3}$ & NR & NR & NR & NR \\
\hline
\end{tabular}

Fuente: Elaboración propia a partir de Rena.ve

Figura 10: Componentes de la matriz orgánica.

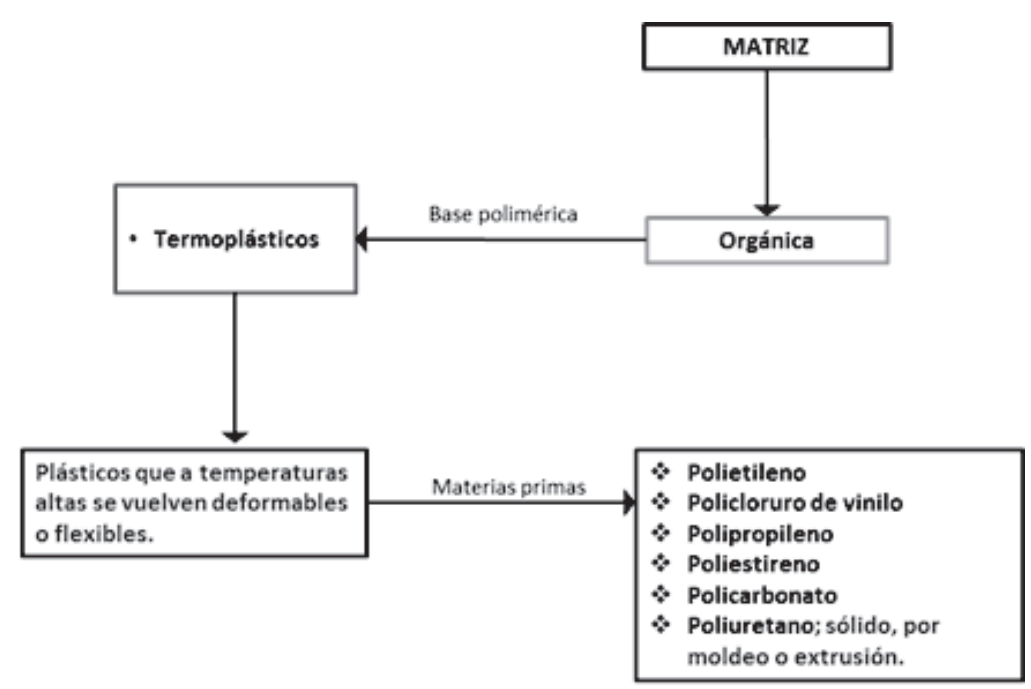

Fuente: Polímeros Termoplásticos, a partir de la clasificación realizada por Mott, 2009. 
LÍNEA DE INVESTIGACIÓN: ARQUITECTURA, CIUDAD Y AMBIENTE

Tabla 4: Propiedades físicas y térmicas de las materias primas de Materiales Compuestos de matriz polimérica (Termoplásticos).

\begin{tabular}{|c|c|c|c|c|c|c|c|c|c|}
\hline \multirow[b]{2}{*}{ Matriz } & & \multirow[b]{2}{*}{ Materia prima } & & \multicolumn{3}{|c|}{ Propiedades físicas } & & \multicolumn{2}{|c|}{ Propiedades térmicas } \\
\hline & & & & Densidad & $\begin{array}{c}\text { Punto de } \\
\text { fusión }\end{array}$ & $\begin{array}{l}\text { Punto de } \\
\text { ebullición }\end{array}$ & & Calor específico & $\begin{array}{c}\text { Conductividad } \\
\text { térmica (K) }\end{array}$ \\
\hline \multirow[t]{10}{*}{ Orgánicos } & \multirow{7}{*}{$\begin{array}{l}0 \\
0 \\
0 \\
\bar{\pi} \\
\frac{\pi}{0} \\
0 \\
0 \\
0 \\
0 \\
0 \\
0\end{array}$} & \begin{tabular}{|l} 
Politer eftalato de \\
Etileno (PET) \\
\end{tabular} & & $1,455 \mathrm{~g} / \mathrm{cm}^{3}$ & $160^{\circ} \mathrm{C}$ & NR & & $1,0 \mathrm{kl} /(\mathrm{kg}-\mathrm{k})$ & $0,24 \mathrm{~W} /(\mathrm{m}-\mathrm{k})$ \\
\hline & & Polietileno (PE) & & $\begin{array}{l}945 \text { y } 950 \mathrm{~kg} \\
\text { por m } \mathrm{m}^{3}\end{array}$ & 290 y $350^{\circ} \mathrm{C}$ & $350^{\circ} \mathrm{C}$ & $\mathrm{H}$ & 1800 & 0,5 \\
\hline & & $\begin{array}{l}\text { Policloruro de vinilio } \\
\text { (PVC) }\end{array}$ & & $1,4 \mathrm{~g} / \mathrm{cm}^{3}$ & $80^{\circ} \mathrm{C}$ & $-13,9+/-0,1$ & & $0,38(\mathrm{cal} / \mathrm{g})$ & NR \\
\hline & & Polipropileno (PP) & & $0,95 \mathrm{~g} / \mathrm{cm}^{3}$ & $173^{\circ} \mathrm{C}$ & NR & & $1700-1900$ & $23 \mathrm{C}(\mathrm{W} \mathrm{m}-1 \mathrm{k}-1)$ \\
\hline & & Poliestireno (PS) & & 1050 & $100^{\circ} \mathrm{C}$ & NR & & $13001 / \mathrm{kg}-\mathrm{k}$ & $0,03 \mathrm{~W}$ k-1 m-1 \\
\hline & & Policarbonato (PC) & & $1,20 \mathrm{~g} / \mathrm{cm}^{3}$ & $130^{\circ} \mathrm{C}$ & $250^{\circ} \mathrm{C}$ & & $12001 /(\mathrm{K}-\mathrm{kg})$ & $0,19-0,22 \mathrm{~W} / \mathrm{m}-\mathrm{k})$ \\
\hline & & Poliuretano (PU) & $R$ & $35\left(\mathrm{~kg} / \mathrm{m}^{3}\right)$ & NR & NR & & \multirow{2}{*}{$18001 / \mathrm{kg}-\mathrm{K}$} & $0,020(\mathrm{~W} / \mathrm{m}-\mathrm{K})$ \\
\hline & & & $F$ & $30\left(\mathrm{~kg} / \mathrm{m}^{3}\right)$ & NR & NR & & & $0,024(\mathrm{~W} / \mathrm{m}-\mathrm{K})$ \\
\hline & & & & Rm rígido & & & & H Alta densidad & \\
\hline & & & & Fm flexible & & & & L Baja densidad & \\
\hline
\end{tabular}

Fuente: Elaboración propia a partir de Ntic.Educación.es

\section{Usos en la arquitectura de los materiales compuestos de matriz orgánica}

Por ser económico, de fácil instalación y montaje, el policloruro de vinilo, comúnmente conocido como PVC, es un material usado frecuentemente en los proyectos arquitectónicos, especialmente en las tuberías hidráulicas y sanitarias, aunque además se emplea en casas prefabricadas (Ver figura 9). Este material se caracteriza por su gran resistencia y durabilidad, y por su adaptabilidad a diversas condiciones climáticas.

Policarbonato: la principal aplicación del policarbonato es en las cubiertas de edificios, estadios y fábricas, porque las características del material permiten el paso de la luz, pero no de los rayos ultravioleta.

"El policarbonato alveolar (...), presenta un alto índice de transmisión luminosa, ayudando al aprovechamiento de la luz natural. Su estructura molecular es una base fundamental del material, haciéndolo resistente tanto a altas temperaturas, cambios climáticos fuertes, al fuego y también a los altos impactos" (Acrílicos $y$ formas, 2014).
Las diferencias básicas entre los materiales compuestos de las tres matrices son: los polímeros termoplásticos poseen densidades más bajas que los metales y los materiales cerámicos; los coeficientes de expansión térmica en los polímeros son mucho más altos, aproximadamente cinco veces el valor de los metales y 10 veces el de los cerámicos; los polímeros tiene puntos de fusión a temperaturas muy bajas; el calor específico es mayor de dos a cuatro veces el de los metales sobre los cerámicos; la conductividad térmica de los cerámicos es de alrededor de tres órdenes de magnitud más bajos que los de los metales y tienen grandes propiedades de aislamiento eléctrico (Materiales Compuestos, 2014).

La carga ambiental que genera la fabricación de un Material Compuesto y su desempeño, en términos de eficiencia y de manejo de residuos, logra optimizar los recursos y mitigar el impacto ambiental. Por lo tanto, la pregunta que se planteó la investigación fue: ¿Cuáles serán los componentes primarios (materias primas), utilizados en la fabricación de Materiales Compuestos que menor impacto generen en los ecosistemas? Para responder a esta pregunta se seleccionaron las materias primas que más 
se utilizan en la industria de la construcción, que corresponden a los componentes de las matrices anteriormente expuestas, y se les aplicó la herramienta de evaluación ambiental SimaPro.

\section{METODOLOGÍA}

Para evaluar el impacto ambiental generado por los componentes de los Materiales Compuestos incluidos en el artículo, se utilizó la herramienta de evaluación SimaPro (SimaPro versión 7.3, Faculty): Éste es un programa desarrollado por la empresa holandesa PRé Consultants, que permite realizar Análisis de Ciclo de Vida mediante el uso de bases de datos de inventario propias (creadas por el usuario) y bibliográficas (BUWAL, IDEMAT, ETH, IVAM).

"Es una herramienta profesional para almacenar, analizar y realizar un seguimiento del rendimiento ambiental de los materiales. Con esta herramienta se facilita el análisis y la representación gráfica de ciclos complejos de un modo sistemático y transparente" (Pré Consultants, 2014).

El software SimaPro, evalúa el impacto en 11 variables, agrupadas en tres categorías. La primera categoría es la salud humana y sus variables son: Partículas cancerígenas, orgánicos respirados (sustancias orgánicas inhaladas) e inorgánicos respirados (sustancias inorgánicas inhaladas). La segunda categoría que corresponde al análisis del ecosistema y sus variables son: cambio climático, radiación, capa de ozono y eco toxicidad (en agua dulce y tierra). La tercera categoría compete a los recursos en las siguientes variables; acidificación y eutrofización, uso de la tierra, minerales y combustibles fósiles. El método de evaluación que utiliza el software es: Eco-Indicador 99 y Ecopuntos 97 (Uche, Raluy, Serra y Valero, 2014).

Figura 11: Aplicación del PVC en una vivienda prefabricada, 2014.
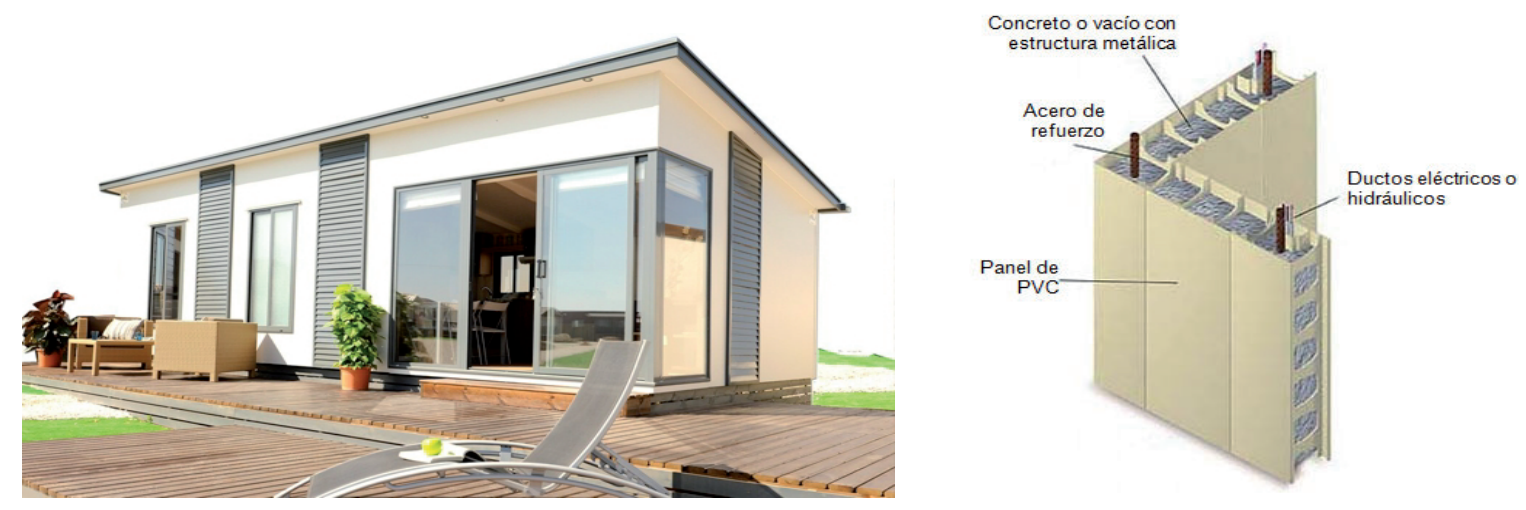

Fuente: Casasprefabricadas24.com

Figura 12: Aplicación del policarbonato.
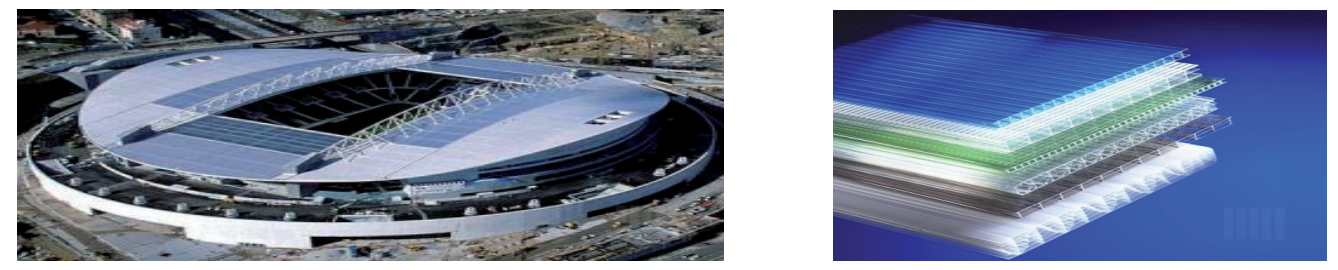

Fuente: Orzare.com 
LÍNEA DE INVESTIGACIÓN: ARQUITECTURA, CIUDAD Y AMBIENTE

\section{RESULTADOS Y DISCUSIÓN}

\section{Evaluación de impacto ambiental: componentes de Matriz Metálica}

Para la evaluación del impacto ambiental generado por los Materiales Compuestos de matriz metálica se seleccionaron: el aluminio, el titanio y el magnesio por ser los materiales más utilizados en proyectos arquitectónicos.

- Aluminio: aluminium, primary, at plan/RER U (ecoinvent, unit processes), (base de datos bibliografía Simapro)

La producción de aluminio, como se aprecia en la Figura 13, genera impactos ambientales especialmente en dos categorías: salud humana y recursos. Muy alto en la categoría recursos, por la gran cantidad de energía empleada en su producción, que proviene de combustibles fósiles (130\%), y medio por el impacto a la variable minerales (38\%). El impacto en la salud humana es alto, siendo causado por las sustancias inorgánicas inhaladas por los trabajadores vinculados al proceso de extracción de materias primas y fabricación del aluminio (110\%) y por la generación de partículas cancerígenas (45 $\%)$. En la categoría ecosistema la única variable que se ve impactada es la de cambio climático (28\%).

- Titanio: titanium zinc plate, without pre-weathering, at plan/DE S (ecoinvent, unit processes), (base de datos bibliografía Simapro).

Como se aprecia en la Figura 14, la producción de titanio genera impacto ambiental en las tres categorías. Muy alto en la categoría de ecosistema, específicamente en la variable de eco toxicidad (150\%). Medio en la categoría de salud humana, por las sustancias inorgánicas inhaladas por los trabajadores vinculados al proceso de extracción de materias primas y fabricación del titanio (65\%). Y también medio en la categoría recursos, por la gran cantidad de energía empleada en su producción, que proviene de combustibles fósiles (55\%). Cabe señalar que, aunque en menor cantidad o proporción, la demanda de titanio en la arquitectura, implica la generación de partículas cancerígenas, contribuye con el calentamiento global y genera residuos que acidifican y eutrofizan los ecosistemas.

Figura 13: Indicadores de impacto ambiental del aluminio

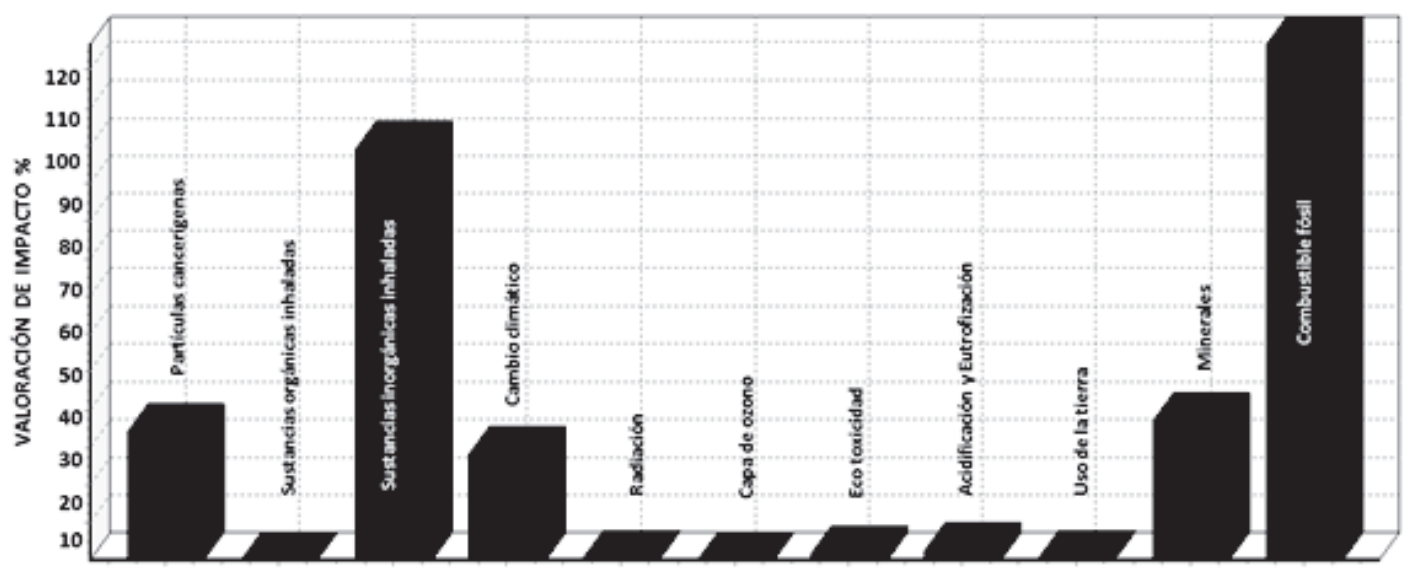

Fuente: a partir del SimaPro versión faculty 7.3 
Figura 14: Indicadores de impacto ambiental del titanio

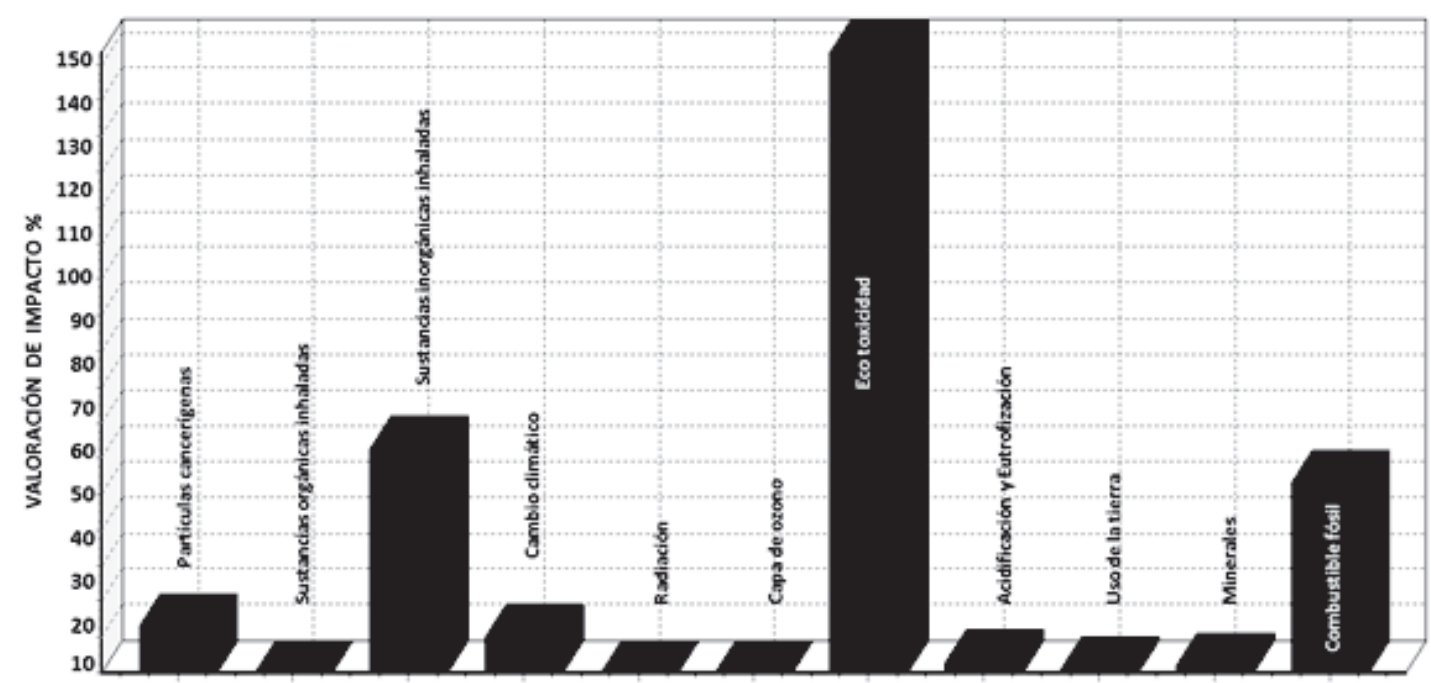

Fuente: a partir del SimaPro versión faculty 7.3

- Magnesio: magnesium at plan/RER S (ecoinvent, unit processes), (base de datos bibliografía Simapro).

La producción de magnesio, como se aprecia en la Figura 15, genera impacto ambiental en las tres categorías. Muy alto en la categoría de ecosistema, específicamente en la variable de cambio climático (170 \%). Alto en la categoría recursos, por la gran cantidad de energía empleada en su producción, que proviene de combustibles fósiles (115\%). Y medio en la categoría de salud humana, por las sustancias inorgánicas inhaladas por los trabajadores vinculados al proceso de extracción de materias primas y fabricación del magnesio (44 \%). Cabe destacar que, aunque en menor cantidad o proporción, la demanda de magnesio en la arquitectura, implica la generación de partículas cancerígenas.

\section{Evaluación de impacto ambiental, componentes de Matriz Cerámica}

Para la evaluación del impacto ambiental generado por los Materiales Compuestos de matriz cerámica se seleccionaron el vidrio y la cerámica NBK.

El primero porque las características propias del vidrio, como son sus propiedades estéticas, de transparencia y reciclado, han hecho que sea un material utilizado en casi todos los proyectos de arquitectura. Y la cerámica NBK por ser un material actualmente bastante utilizado, y que ha diversificado el diseño de fachadas y envolventes arquitectónicas.

- Vidrio: Flat glass plan/RER IS (ecoinvent, unit processes), (base de datos bibliográficos de SimaPro).

Como se aprecia en la Figura 16, la producción de vidrio genera impactos ambientales especialmente en dos categorías: salud humana y recursos. El impacto es muy alto en la categoría de recursos, específicamente por los minerales que se emplean para la producción del vidrio (150 \%); y un poco menor por la gran cantidad de energía empleada en la producción del vidrio, que proviene de combustibles fósiles (50\%). 
LÍNEA DE INVESTIGACIÓN: ARQUITECTURA, CIUDAD Y AMBIENTE

Figura 15: Indicadores de impacto ambiental del magnesio

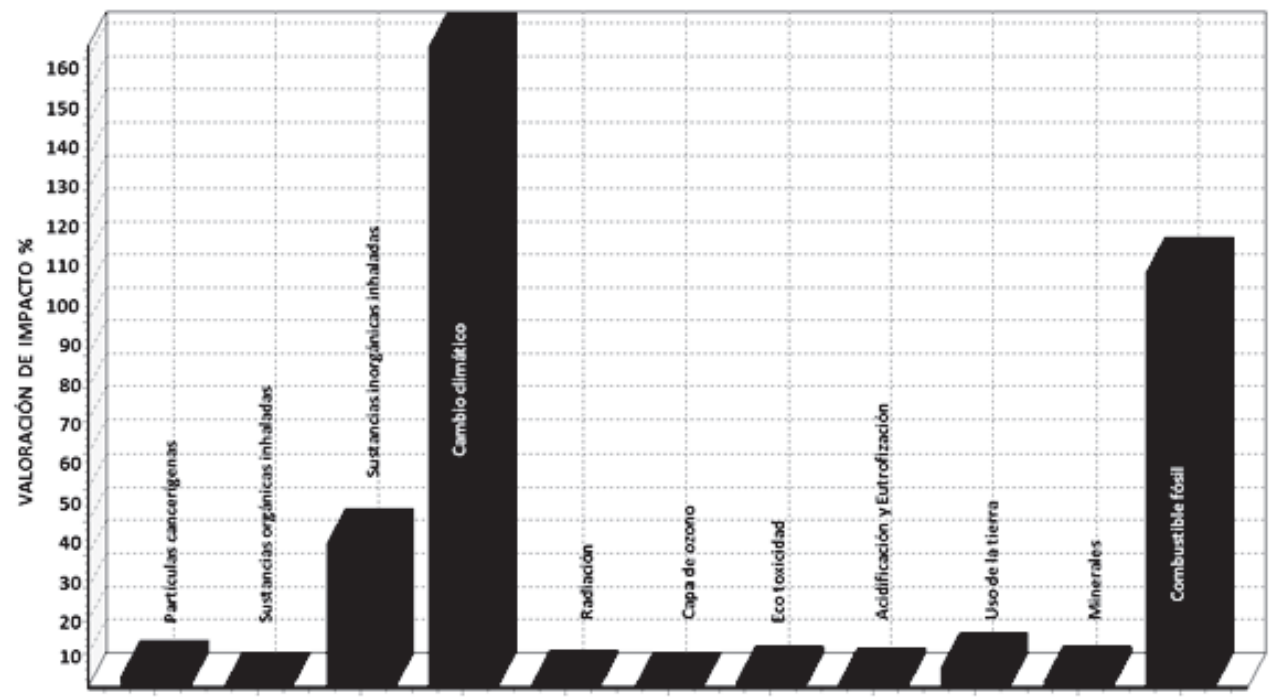

Fuente: a partir del SimaPro versión faculty 7.3

Figura 16: Indicadores de impacto ambiental del vidrio

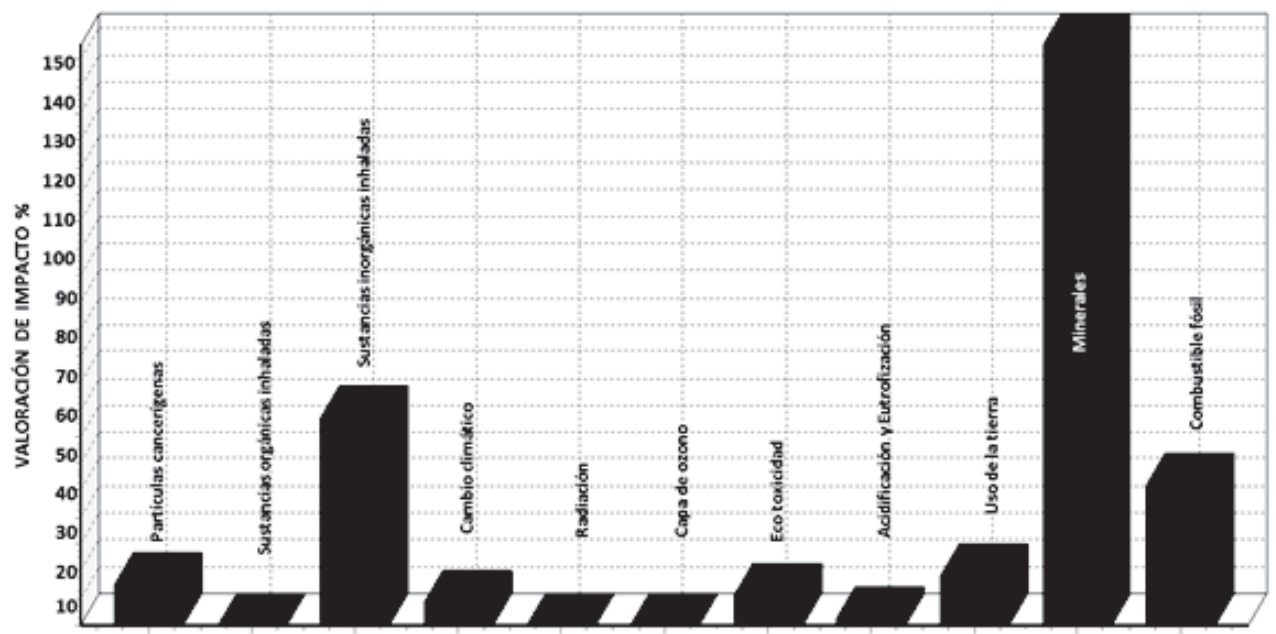

Fuente: a partir del SimaPro versión faculty 7.3

En la categoría de salud humana el impacto es medio ( $70 \%$ ) y es causado por las sustancias inorgánicas inhaladas por los trabajadores vinculados al proceso de extracción de materias primas y fabricación del vidrio. Cabe subrayar que, aunque en menor cantidad o proporción, la demanda de vidrio en la arquitectura, implica la generación de partículas cancerígenas y de materias residuales, ecotóxicas, también contribuye con el calentamiento global.

- NBK: Ceramic plant /CH/IS; (ecoinvent, unit processes), (base de datos bibliográficos de SimaPro). 
Como se aprecia en la Figura 17, la producción de la cerámica NBK genera impactos en las tres categorías. El impacto es muy alto en la categoría salud humana por causa de la inhalación de sustancias inorgánicas durante los procesos de producción (140\%), y por la producción de partículas cancerígenas (30 \%). Los impactos en la categoría recursos son muy altos por el elevado consumo de combustibles fósiles durante el proceso de fabricación (130 \%), y medio por el impacto sobre las variables uso de la tierra $(70 \%)$ y minerales $(60 \%)$. En menor proporción, aunque no desestimable, se impacta la categoría ecosistemas, especialmente en las variables generación de residuos eco tóxicos (35\%), cambio climático (20\%), y acidificación y eutrofización de los ecosistemas (10\%).

\section{Evaluación de impacto ambiental, componentes de Matriz Orgánica (Termoplásticos)}

Para la evaluación de impacto ambiental de los Materiales Compuestos de matriz or- gánica, se han seleccionado tres polímeros termoplásticos por ser los más utilizados en la construcción: el policloruro de vinilo (PVC), el policarbonato y el poliuretano.

- PVC: polyvinyl chloride/ E of project Industry data 2.0, (base de datos bibliográficos de Simapro).

La producción de PVC, como se aprecia en la Figura 18, genera impacto ambiental especialmente en dos categorías: salud humana y recursos. El impacto es muy alto en la salud humana, por efecto de la generación de partículas cancerígenas (135\%), y por la inhalación de sustancias inorgánicas (28 \%). En la categoría de recursos la variable más impactada es la de consumo de combustibles fósiles (90\%). Cabe destacar que, aunque en menor cantidad o proporción, la demanda de PVC en la arquitectura, contribuye con el cambio climático.

- PC: Polycarbonate, at plant/RER U of Project Ecoinvent unit processes, (base de datos bibliográficos de Simapro).

Figura 17: Indicadores de impacto ambiental del NBK

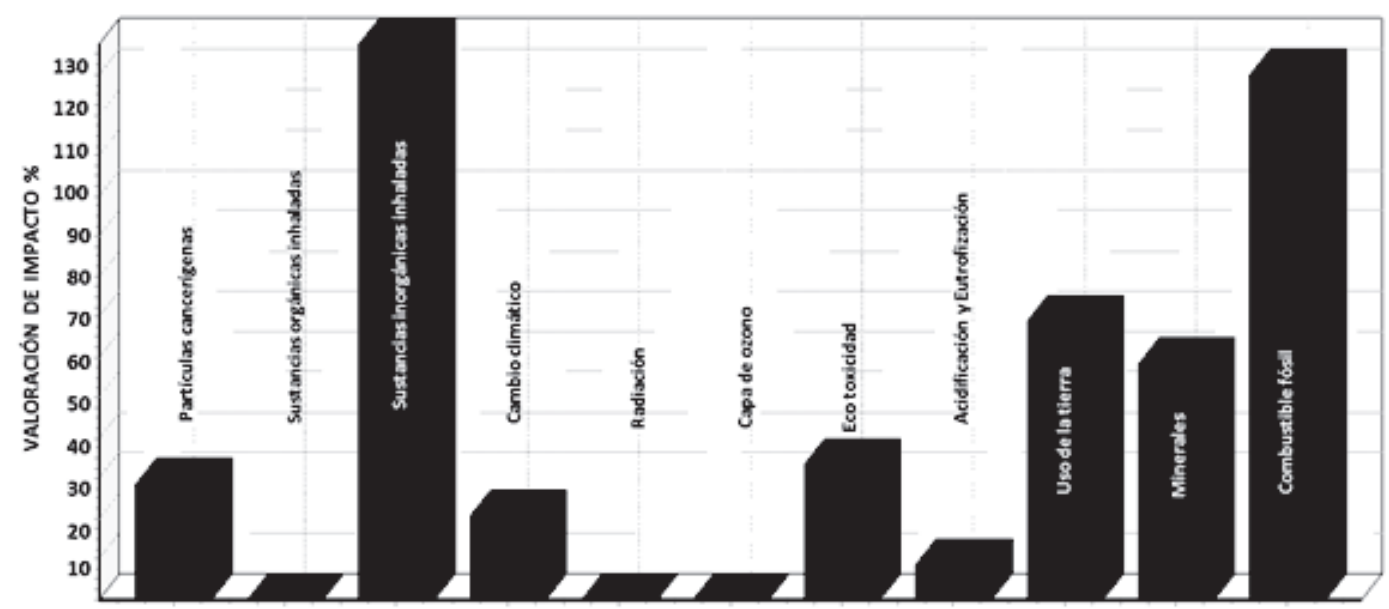

Fuente: a partir del SimaPro versión faculty 7.3 
LÍNEA DE INVESTIGACIÓN: ARQUITECTURA, CIUDAD Y AMBIENTE

Figura 18: Indicadores de impacto ambiental del PVC

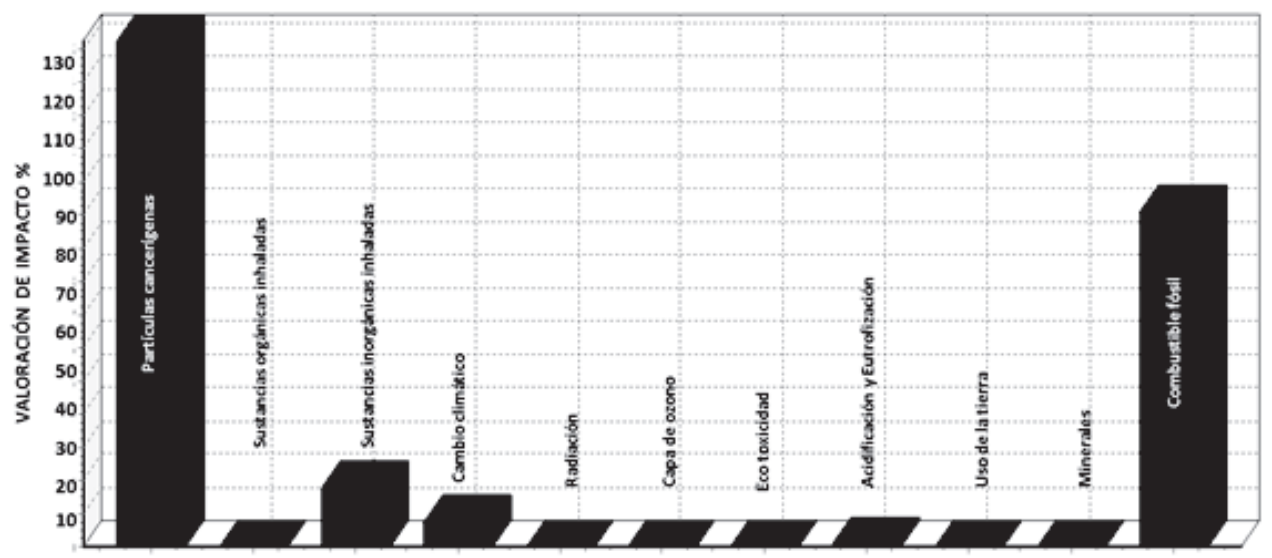

Fuente: a partir del SimaPro versión faculty 7.3

Figura 19: Indicadores de impacto ambiental del policarbonato

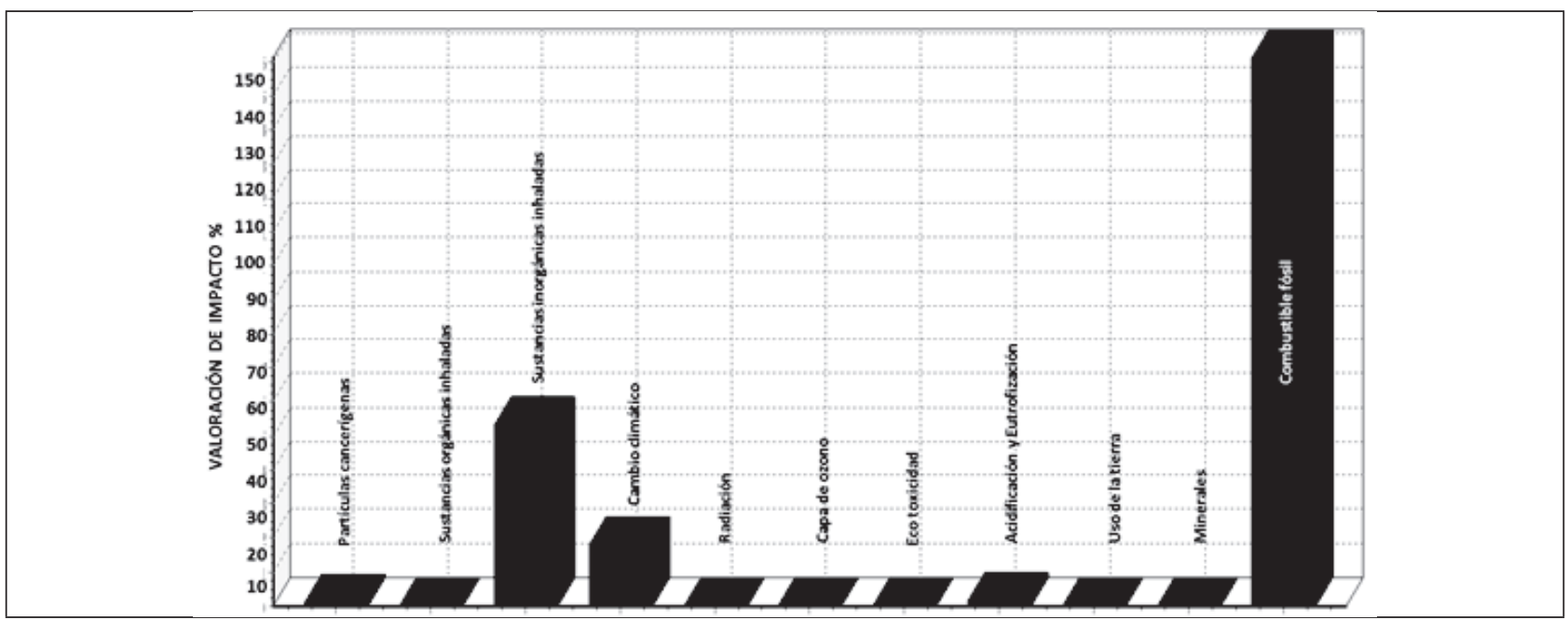

Fuente: a partir del SimaPro versión faculty 7.3

La producción de policarbonato, como se aprecia en la Figura 19, genera impacto ambiental especialmente en dos categorías: salud humana y recursos. El impacto es alto en la salud humana, por la inhalación de sustancias inorgánicas (64\%). En la categoría de recursos, la variable de consumo de combustibles fósiles recibe un impacto muy alto (160\%). Cabe destacar que, aunque en menor cantidad o proporción, la demanda de policarbonalto en la arquitectura, contribuye con el cambio climático.
- Poliuretano: Polyurethane, flexible foam, at plant/RER S ecoinvent, unit processes, (base de datos bibliográficos de Simapro).

La producción de poliuretano, como se aprecia en la Figura 20, genera impacto ambiental especialmente en dos categorías: salud humana y recursos. El impacto es alto en la salud humana, por la inhalación de sustancias inorgánicas (54\%). En la categoría de recursos la variable de consumo de combustibles fósiles recibe un impacto muy alto (150\%). Cabe destacar que, 
aunque en menor cantidad o proporción, la demanda de poliuretano en la arquitectura, contribuye con el cambio climático.

\section{DISCUSIÓN}

Los Materiales Compuestos de matriz metálica analizados con SimaPro arrojan los siguientes resultados (ver tabla 5). El aluminio tiene el mayor impacto en los combustibles fósiles, las sustancias inorgánicas inhaladas y en los minerales. El mayor impacto del titanio se genera en la eco-toxicidad, en las sustancias inorgánicas inhaladas y en los combustibles fósiles. El mayor impacto del magnesio se genera en el cambio climático, combustibles fósiles y en las sustancias inorgánicas inhaladas. Comparativamente el mayor impacto se genera en la categoría de los recursos, específicamente en el consumo de combustible fósil para la elaboración de productos elaborados con metales ligeros. En segundo lugar el impacto se genera en la variable de eco-toxicidad y en las sustancias inorgánicas inhaladas, variables que correspon- den a las categorías del eco-sistema y de la salud humana respectivamente.

Los compuestos de matriz cerámica analizados con SimaPro generan el siguiente resultado (ver tabla 6). El vidrio presenta el mayor impacto en los minerales empleados para su fabricación. En segundo lugar las sustancias inorgánicas inhaladas en el procesos de producción del vidrio y en tercer lugar el combustible fósil empleado para la extracción de las materias primas y la elaboración del vidrio.

Los compuestos de matriz orgánica analizados con SimaPro generan el siguiente resultado (ver tabla 7). El mayor impacto se genera en la categoría de combustibles fósiles, principalmente por la energía requerida para su fabricación. En segundo lugar corresponde a la salud humana, derivado de la manipulación de sustancias cancerígenas que producen las partículas en suspensión en los procesos de fabricación de los productos elaborados con estos compuestos. La tercera categoría de impacto se genera en la capa de ozono.

Figura 20: Indicadores de impacto ambiental del poliuretano flexible

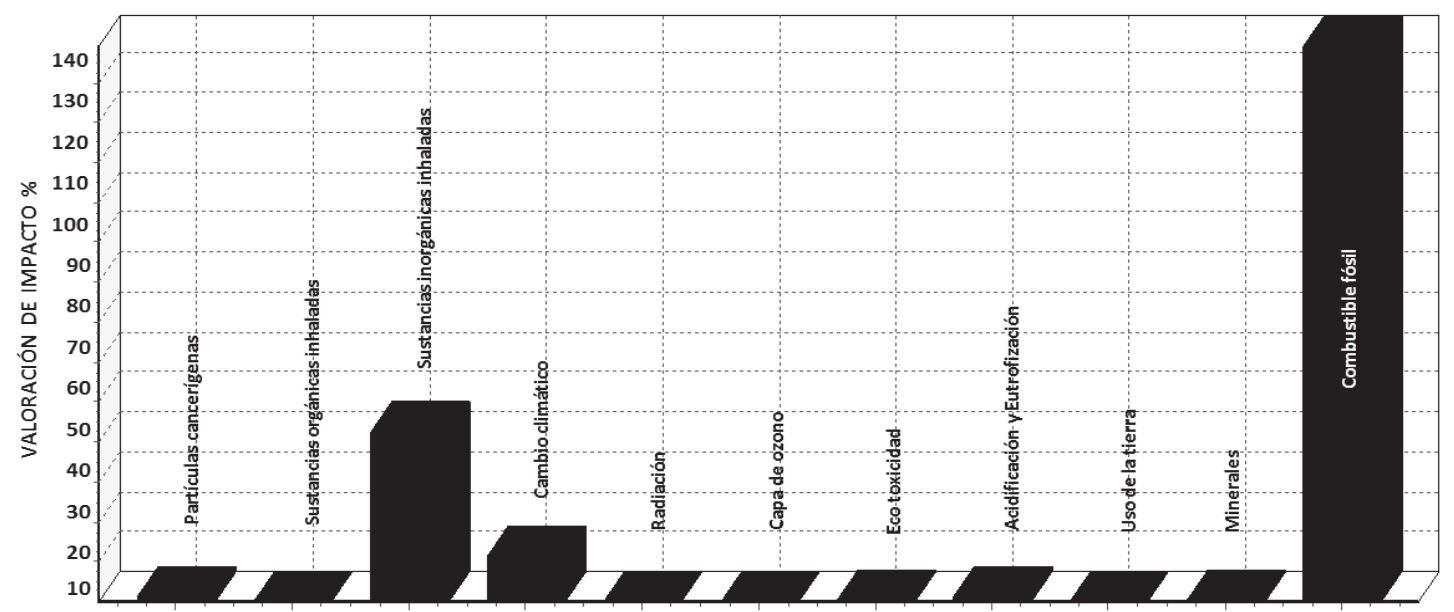

Fuente: a partir del SimaPro versión faculty 7.3 

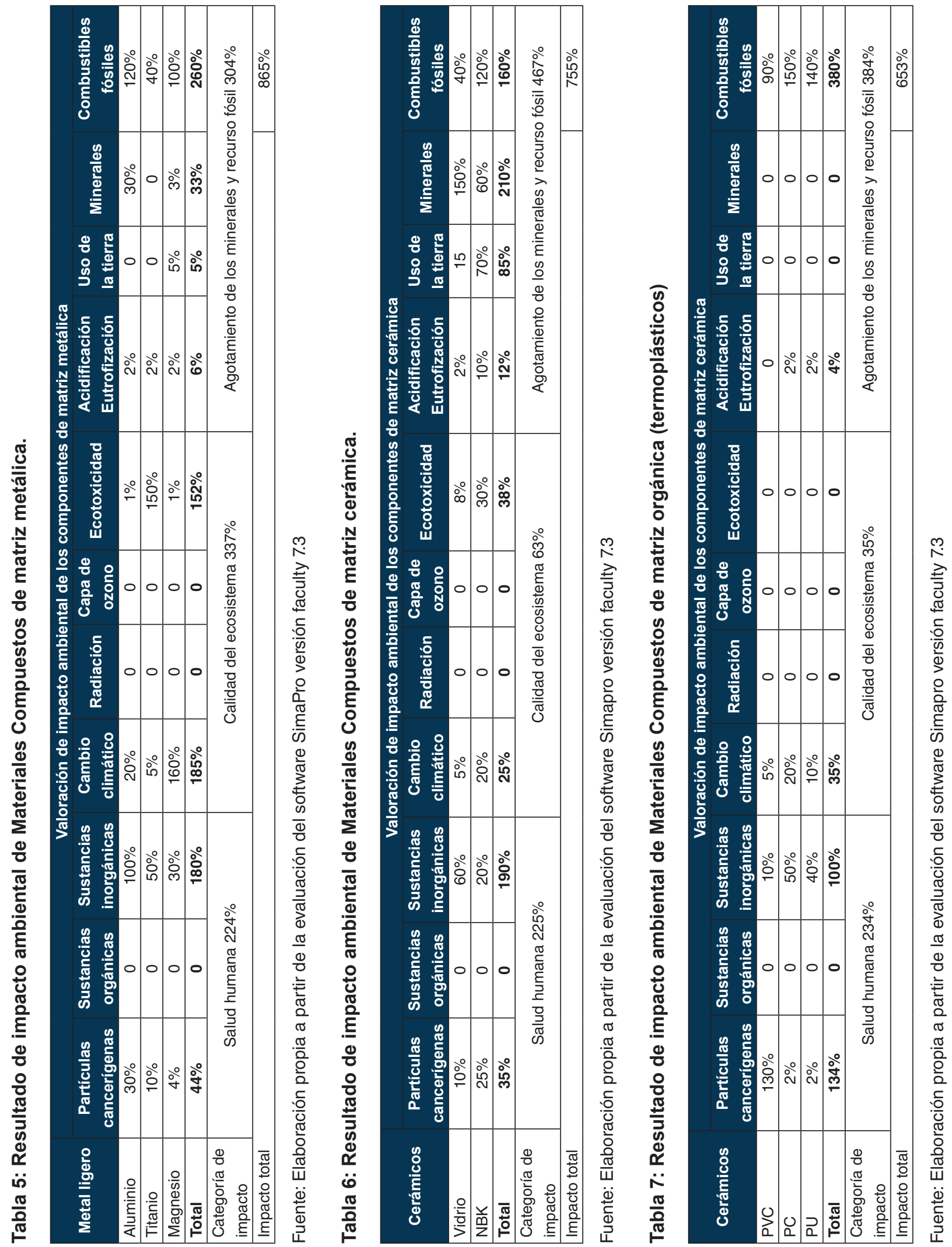


\section{CONCLUSIONES}

Analizado el impacto ambiental que generan los Materiales Compuestos que se utilizan en la arquitectura, se concluye que los compuestos de matriz metálica son los que mayor carga ambiental aportan a los ecosistemas, en segundo lugar los compuestos de matriz cerámica, mientras que los compuestos de matriz orgánica son lo que menos carga ambiental aportan al ambiente.

\section{SOBRE LOS AUTORES}

Cortés Cely, Oscar: Arquitecto, candidato a magister en arquitectura bioclimática de la Escuela de Arquitectura y Diseño de América La- tina y el Caribe, ISTHMUS. Miembro del grupo de investigación Territorio y Habitabilidad. Docente investigador Facultad de Arquitectura de la Universidad de América del año 2010 a 2014. Diseñador Independiente. Correo electrónico: arqcortescely@gmail.com

Molina Prieto, Luis Fernando: ArquitectoInvestigador con amplia experiencia en temas de sostenibilidad urbana. Miembro del grupo de investigación Territorio y Habitabilidad. Docente investigador Facultad de Arquitectura Universidad de América. Por su trabajo ha recibido varios reconocimientos, dentro de los que se destaca el primer lugar en el Premio de reportaje sobre biodiversidad, 2004, entregado en Bangkok, Tailandia. Correo electrónico: Imolinaprieto@gmail.com

\section{REFERENCIAS}

Edwards, B. (2011) Guía básica de la Sostenibilidad. Barcelon. $2^{\circ}$ edición revisada y ampliada. Gustavo Gil. p. 233.

Mott, R. (2009) Resistencia de Materiales. México DF. $5^{\circ}$ edición. Pearson Educación. p. 792.

Takeuchi, N. (2010) Nanociencia y Nanotecnología. México DF.: Fondo de Cultura Económica. P. 142.

Miravete, A. \& Castejón, L. (2002) Materiales Compuestos. Revista Elisava TDD. Disponible en: http://tdd.elisava. net/coleccion/20/miravete-_ castejon-es

IngeMecánica (En Línea) Tutorial No. 110. Recuperado el 9 de mayo de 2014. Disponible en: http://ingeme- canica.com/tutorialsemanal/ tutorialn110.html

Herramientas.educa.madrid.org (En línea) Berilio. Recuperado el 9 de mayo de 2014. Disponible en:

http://herramientas.educa. madrid.org/tabla/2abundancia/ be2.html

Acrílicos y formas (En línea) Recuperado el 13 de julio de 2014. Disponible en web: http://www.acrilicosyformas. com/producto.html

Serrano, L. (En línea) Materiales Compuestos. (ref. De 09 de junio de 2014). Disponible en web: http://es.scribd.com/ doc/139448200/MaterialesCompuestos-Esfuerzos-pdf

Tecnología de los plásticos (En línea) Recuperado el 09 de junio de 2014. Disponible en: http://tecnologiadelosplasticos.blogspot.com/2011/06/ polipropileno.html

Pré Consultans bv, Software SIMAPRO versión 7.3 Faculty (en línea). (ref. De 30 de abril de 2014). Disponible en web: http://www.pre-sustainability.com/simapro, abril de 2014

Plataforma Arquitectura. (en línea). (ref. De 09 de julio de 2014). Disponible en web:

Http://www. plataformaarquitectura.cl/2010/08/19/ el-vidrio-nuevas-tecnologiasy-prototipos/

MINISTERIO DE AMBIENTE, VIVIENDA Y DESARROLLO TERRITORIAL-MAVDT (en línea). (ref. De 23 de mayo de 2014). Disponible en web: http://www.minambiente.gov. co/web/index.html, mayo de 2014. 
LÍNEA DE INVESTIGACIÓN: ARQUITECTURA, CIUDAD Y AMBIENTE

Stupenengo, F. (2011) Materiales y materias primas: Materiales compuestos. Guía didáctica, Capítulo 10. Argentina: Ministerio de Educación. Instituto Nacional de Educación Tecnológica INET, 27 p.

Wikipedia. (En línea). (ref. De 02 de junio de 2014). Disponible en web: http:// es.wikipedia.org/wiki/silicio.

Polímeros de los termoplásticos. (En línea). (ref. De 02 de junio de 2014). Disponible en web: ttp://quantum.cucei.udg.mx/ saguf/descargas/ termoplasticos.

Da Costa, C., Velazco, F. \& Torralba, J. (2000) Materiales compuestos de matriz metálica. $1^{\circ}$ Parte: tipos, propiedades y aplicaciones. Revista de Metalurgia. No. 36, Ps. 179 - 192.

Panel compuesto en Alucobond. (en línea). (ref. De 11 de junio de 2014). Disponible en web: http://www.alucobond. com/alucore-technical-data. html?\&l=4.

Hernández, J. \& García, J. (2014) Los materiales compuestos y su desarrollo actual. Revista en línea, Ciencia y Desarrollo. (en línea). (ref. De 11 de junio de 2014). Disponible en: http://www.cyd.conacyt. gob.mx/240/Articulos/materialescompuestos/materialescompuestos1.html.

Douglas, H. (2014) (en línea). (ref. De 12 de junio de 2014). Disponible en web: http://www.hunterdouglascontract.com/facades/terracotta_ facade.jsp.

Materiales Compuestos (2014) Clasificación de los materiales para manufactura. Revista en línea, Ing. Mecánica. Tecnología Mecánica. (En línea). (ref. De 12 de junio de 2014). Disponible en web: iihttp://materias.fcyt.umss.edu. bo/tecno-ii/pdf/cap-17.pdf

Fibras sintéticas y artificiales. (2014) (en línea). (Ref. De 12 de junio de 2014). Disponible en web: http://thepoliestiren.blogspot.com/2013/02/ el-poliester-y-todas-sus-caracteristicas.html.

Uche, J., Raluy, G., Serra, L., \& Valero, A. (2014) Aplicación de La Metodología de Análisis de Ciclo De Vida (Acv) para la Evaluación Ambiental de Desaladoras". Revista en línea, Gestión Ambiental, Huella Ecológica de Carbono e Hídrica. (En línea). (Ref. De 12 de junio de 2014). Disponible en web: https://www.academia.edu/5025926/gestión ambiental, huella ecológica de carbono e hídrica.

Guggenheim-bilbao.es (En Línea) Disponible en: http:// www.guggenheim-bilbao.es/ el-edificio/el-arquitecto/.

\section{FIGURAS E IMÁGENES}

http://ntic.educacion.es/ w3/eos/MaterialesEducativos/ mem2002/quimica/ http://www.alucobondusa. $\mathrm{com} / \mathrm{blog} /$ architects-paintmedical-office-tower-withcustom-alucobond-plus/\#. u7_-s5r5meg

http://wikifab.dimf.etsii.upm.es/wikifab/index. php/09442_Proyecto_de_ Automatizaci\%C3\%B3n:Planta_de_extrusi\%C3\%B3n_ d e _ a l u m i n i o. Fabricaci\%C3\%B3n_y_distribuci\%C3\%B3n

http://www.latercera.com/ noticia/cultura/2014/05/1453577003-9-arquitecto-frank-gehry-gana-premio-principe-deasturias-de-las-artes.shtml

http://ntic.educacion.es/ w3/eos/MaterialesEducativos/ mem2002/quimica/

http://www. hunterdouglas.com.co/ap/co/galeria-de-proyectos/fachadas/ fachadas-ventiladas/revestimiento-ceramico-nbk-hunterdouglas/centro-comercial-andino

http://www.fierasdelaingenieria.com/la-innovacion-delvidrio-en-la-arquitectura-alrededor-del-mundo/

http://ntic.educacion.es/ w3/eos/MaterialesEducativos/ mem2002/quimica/

http://www.casasprefabricadas24.com/casas-de-pvcprefabricadas/ 